\title{
Nação, nacionalismo e globalização
}

ENTREVISTA COM PAULO NOGUEIRA BATISTA JR.

$\mathrm{E}$ M ENTREVISTA a ESTUdOS AVANÇADOS no dia 4 de março, o economista Paulo Nogueira Batista Jr., diretor-executivo do Brasil no FMI (Fundo Monetária Internacional), declarou que não se pode "abrir mão do Estado Nacional" mesmo diante do processo de globalização. "Não existem instâncias supranacionais capazes de substituí-lo. E os mercados não funcionam sem Estado".

Paulo Nogueira Batista Jr. é professor e pesquisador, atualmente licenciado, da Fundação Getúlio Vargas em São Paulo. Foi secretário especial de assuntos econômicos do Ministério do Planejamento em 1985-1986, durante a gestão de João Sayad, e assessor para assuntos de dívida externa do ministro da Fazenda, Dilson Funaro, em 1986-1987. Chefiou o Centro de Estudos Monetários e de Economia Internacional da Fundação Getúlio Vargas do Rio de Janeiro de 1986 a 1989. Foi pesquisador visitante no Instituto de Estudos Avançados da Universidade de São Paulo entre 1996 e 1998 e, novamente, entre 2002 e 2004 . Exerce atualmente a função de diretor-executivo no FMI, onde representa um grupo de nove países (Brasil, Colômbia, Equador, Guiana, Haiti, Panamá, República Dominicana, Suriname e Trinidad e Tobago).

$\mathrm{O}$ economista respondeu às perguntas por escrito e as enviou por e.mail à redação de ESTUDOS AVANÇADOS. Leia, a seguir, a íntegra da entrevista.

\section{ESTUDOS AVANÇADOS - Qual o papel que o nacionalismo pode exercer nos dias de hoje?}

Paulo Nogueira Batista Jr. - O nacionalismo é uma força histórica muito poderosa, que está longe de esgotada. Para os países da periferia do mundo, o nacionalismo é um instrumento de mobilização provavelmente imprescindível para a superação do atraso e do subdesenvolvimento, como parece indicar a experiência histórica, recente e remota. Digo "parece", porque as chamadas lições da história nunca são muito claras e estão sempre abertas a interpretações divergentes. "Não há fatos, só interpretações", dizia Nietzsche. Feita essa ressalva, na América Latina há casos de países que abraçaram com fervor as doutrinas "globalitárias" e não foram nada bem-sucedidos. A Argentina dos anos 1990 é o exemplo mais dramático e mais conhecido. Os países menos desenvolvidos precisam, no meu entender, tomar distância de ideologias antinacionais, cosmopolitas ou "globalizantes" - e já começaram a fazê-lo. Como escreveu Euclides 
da Cunha no final do século XIX, “o cosmopolitismo é o regime colonial do espírito". Esse regime colonial custa a morrer, mas não vai durar para sempre. O quadro econômico e político na América do Sul já mudou substancialmente nos últimos dez anos.

ESTUdos AVANÇADOs - Em face da globalização, é possível dizer que o nacionalismo não faz mais sentido, ou pode-se ainda constatar, por trás das multinacionais, a força de algumas nações economicamente privilegiadas?

P. N. B. Jr. - Continuo com a opinião de que há muito exagero nessas discussões sobre "globalização". A internacionalização das economias não é, em geral, tão abrangente, inédita e irreversível quanto sugerem as interpretações mais divulgadas. O próprio termo "globalização" parece um tanto forçado, como procurei mostrar em trabalho publicado nesta revista e em alguns capítulos dos meus dois livros mais recentes (Batista Jr., 1998; 2002, p.37-71; 2005, p.3-31). Talvez só na área financeira o termo "globalização" possa se aplicar com propriedade, sem induzir a erros e ilusões. $\mathrm{O}$ ceticismo quanto ao alcance da internacionalização tem sido expresso por diversos autores. Por exemplo, no seu último livro, Dani Rodrik (2007, p.196-8) observa que integração econômica internacional permanece muito mais limitada do que se supõe.

Em todo o caso, aceite-se ou não o termo "globalização" como uma descrição adequada do quadro internacional, o papel do Estado Nacional continua crucial, nos países desenvolvidos e nos países em desenvolvimento. Ninguém pode abrir mão do Estado Nacional. Não existem instâncias supranacionais capazes de substituí-lo. E os mercados não funcionam sem Estado.

Nota-se certa duplicidade dos países desenvolvidos. Eles são, como se sabe, a fonte e a origem das teorias econômicas liberais. É o que se ensina nas suas universidades, é o que se propaga mundo afora por meio das entidades multilaterais controladas por esses países, notadamente o Fundo Monetário Internacional (FMI) e o Banco Mundial. E, no entanto, a prática desses países diverge marcadamente da teoria liberal. Em todos os países avançados, o Estado atua de forma importante nas áreas econômica e social, complementando e corrigindo os mercados. A reação liberal, capitaneada por Ronald Reagan nos Estados Unidos e Margareth Thatcher no Reino Unido, não conseguiu reverter inteiramente a tendência de aumento do papel do Estado, que remonta ao início do século XX e se intensificou depois da Grande Depressão da década de 1930. Como costumava dizer James Tobin (1996, p.181), quem venceu a guerra fria não foram economias puras de mercado, mas economias mistas, com forte participação do Estado.

A presença do Estado Nacional se nota, por exemplo, na atuação das empresas "multinacionais" ou "transnacionais", outro termo enganoso, no meu entender. A maior parte das empresas que atuam internacionalmente possui uma base nacional, um centro de gravidade nacional claramente identificável. São geralmente empresas nacionais, que têm forte presença no exterior ou atuam 
em escala mundial. As exceções são as grandes corporações de pequenos países desenvolvidos, como a Suíça, a Suécia ou a Finlândia. Os Estados Nacionais dos países desenvolvidos não se enganam quanto a isso e atuam freqüentemente em defesa das suas "multinacionais". Essas empresas também têm uma dupla face: por um lado, querem ser vistas como "globais" para não suscitar reações nacionalistas nos países onde investem; por outro, não têm constrangimento algum em recorrer ao apoio do seu Estado Nacional quando se trata de disputar concorrências e contratos no exterior, abrir mercados e derrubar barreiras à sua atividade. A atuação dos governos dos Estados Unidos e demais países desenvolvidos na Organização Mundial do Comércio (OMC) e em negociações comerciais bilaterais está em larga medida pautada pela defesa dos interesses das suas corporações "multinacionais", como ressaltou, por exemplo, Joseph Stiglitz (2006; Stiglitz \& Charlton, 2005) em livros recentes.

ESTUDOS AVANÇADOS - Existe alguma relação positiva ou negativa entre politicas nacionalistas e democracia?

P. N. B. Jr. - Nacionalismo e democracia nem sempre andam juntos, como se sabe, mas são perfeitamente compatíveis. Diria que são complementares. Um projeto nacional sem base democrática não é sustentável no longo prazo. Nação sem povo é um conceito vazio. O povo precisa se identificar com a nação, sentir-se representado e considerado nas ações do Estado Nacional. E essa identificação pressupõe democracia. A existência de um regime democrático aumenta as chances de que as políticas do Estado Nacional levem em conta os interesses da maioria. O voto é um contrapeso, ainda que precário, ao poder do dinheiro. Além disso, não se deve perder de vista que a democracia, com todos os seus defeitos e limitações, só é possível no âmbito nacional. Não há democracia no plano internacional. As organizações multilaterais são entidades oligárquicas, em maior ou menor grau, dominadas por um grupo pequeno de países desenvolvidos. Estamos lutando para aumentar a influência de países em desenvolvimento nos organismos internacionais, mas é um processo difícil e lento. Foi o que voltei a constatar, agora por experiência direta, desde que passei a integrar a diretoria executiva do Fundo Monetário Internacional, representando o Brasil e outros oito países da nossa região. É tremenda a força da inércia em instituições como o FMI. As mudanças são possíveis e vamos continuar lutando por elas, mas tudo acontece muito lentamente.

ESTUdOS AVANÇADOS - A política econômica do governo Lula é nacionalista?

P. N. B. Jr. - O governo Lula é um governo ambíguo, mas é mais próximo do nacionalismo do que o seu antecessor - o que não diz grande coisa, reconheço. No governo Fernando Henrique Cardoso, tanto a política econômica como a política externa tiveram um caráter, digamos, cosmopolita. No governo Lula, a política externa foi, desde o início, mais nacionalista ou nacional-desenvolvimentista. Estou me referindo, evidentemente, ao Itamaraty. A interrupção da negociação da Área de Livre-Comércio das Américas (Alca) foi um marco 
dessa reorientação da política econômica externa. O Brasil, a Argentina e outros países tiveram papel central em impedir que a Alca fosse adiante. No âmbito do Ministério da Fazenda e do Banco Central, a evolução tem sido muito mais lenta. No primeiro governo Lula, a política da Fazenda e do Banco Central foi basicamente continuista. Só a partir de 2006, com a saída do ministro Antonio Palocci Filho, é que começaram mudanças no Ministério da Fazenda. No Banco Central, manteve-se a orientação, com alguma flexibilização recente, mas ainda bastante modesta.

De qualquer maneira, no segundo governo Lula, há mais ênfase no crescimento econômico e na defesa da autonomia nacional. O país está mais assertivo. E não está mais tão vulnerável do ponto de vista externo. Esse aspecto é fundamental. Temos uma posição mais forte de balanço de pagamentos. A balança comercial registrou saldos elevados. Durante cinco anos consecutivos, de 2003 a 2007, o Brasil teve superávits no balanço de pagamentos em transações correntes. As reservas internacionais alcançaram um nível recorde.

ESTUDOS AVANCADOS - Existe uma tendência nacionalista corrente em alguns paises da América do Sul?

$P$. N. B. Jv. - Creio que sim. O nacionalismo, tão estigmatizado na década de 1990, voltou a ser valorizado. Na Argentina, na Venezuela, na Bolívia e no Equador, por exemplo. E também no Brasil. A diferença é que o Brasil tem sido mais cauteloso - o que no fundo acaba sendo bom. O importante não é fazer barulho, mas tomar medidas concretas que aumentem a autonomia dos países e o seu poder de negociação internacional.

ESTUdOS AVANÇADOs - A integração dos mercados sul-americanos é uma forma superior de nacionalismo entre as nações em desenvolvimento?

P. N. B. Jv. - Essa talvez seja uma das principais diferenças entre o nacionalismo atual e o de décadas anteriores na nossa região. Há uma ênfase maior na integração sul-americana, uma compreensão de que a atuação conjunta dos países é uma alavanca importante nas atuais condições internacionais. O Brasil até poderia desenvolver o seu projeto nacional individualmente, pois tem tamanho para isso. Mas em conjunto com os vizinhos, ou com boa parte deles, o nosso poder de fogo é maior. Note-se que estamos falando de América do Sul e não mais de América Latina, como nos tempos de Raúl Prebisch, de Celso Furtado e da Cepal. O processo de incorporação do México e da América Central ao espaço econômico dos Estados Unidos avançou muito - América Latina deixou de ser um conceito politicamente operativo, no meu entender.

\section{Referências bibliográficas}

BATISTA JUNIOR, P. N. Mitos da Globalização. Estudos Avançados, Instituto de Estudos Avançados, da Universidade de São Paulo, v.12, n.32, jan./abr. 1998. A economia como ela é... 3.ed. São Paulo: Boitempo, 2002. 
BATISTA JUNIOR, P. N. O Brasil e a economia internacional: recuperacão e defesa da autonomia nacional. Rio de Janeiro: Elsevier, 2005.

RODRIK, D. One Economics, Many Recipes: Globalization, Institutions, and Economic Growth. Princeton: Princeton University Press, 2007.

STIGLITZ, J. E. Making Globalization Work. New York: W. W. Norton, 2006.

STIGLITZ, J. E.; CHARLTON, A. Fair Trade for All: How Trade Can Promote Development. New York: Oxford University Press, 2005.

TOBIN, J. Full Employment and Growth: Further Keynesian Essays on Policy. Cheltenham: Edward Elgar, 1996. 